\title{
ESTUDO DO GESTO EM DANÇAS DE CULTURAS POPULARES SOB UMA PERSPECTIVA SISTÊMICA
}

\author{
Laura Bauermann \\ Doutoranda no Programa de Pós-Graduação em Educação, Escola de Humanidades, \\ Pontifícia Universidade Católica do Rio Grande do Sul \\ Email: laura.bauermann@acad.pucrs.br \\ Jair Felipe Bonatto Umann \\ Professor Assistente do Curso de Graduação em Dança da Universidade Federal do Rio Grande do Sul \\ Doutorando no Programa de Pós-Graduação em Educação, Escola de Humanidades, \\ Pontifícia Universidade Católica do Rio Grande do Sul \\ Email: jair.umann@acad.pucrs.br
}

\section{Resumo}

$\mathrm{O}$ artigo se propõe a analisar a possibilidade de articulação dos princípios que constituem práticas de estudo do gesto expressivo com investigações no campo das danças das culturas populares. Para tanto, assumimos a perspectiva sistêmica de produção do conhecimento. A seguinte pergunta norteia a investigação: é possível que as ferramentas de compreensão do corpo na dança - as quais temos acesso pelos estudos que impregnam as pedagogias contemporâneas em dança - atuem numa abordagem sistêmica ao se relacionarem com o fazer da dança popular? Buscamos o exercício reflexivo a partir de uma pesquisa documental com referências que trabalham com a aprendizagem de movimento no campo da dança e com o universo das danças populares brasileiras. Destacamos as publicações de Christine Roquet (2011), Antônio Nóbrega (2013, 1995) e Graziela Rodrigues (2005). Esta pesquisa realizou-se a partir de um referencial que aborda a característica hologramática e complexa dos fazeres humanos. Com esse estudo, foi possível refletir sobre o trabalho de artistas que dialogam com gestos das danças populares, bem como fundamentar uma argumentação a fim de destacar o que significa um trabalho em dança sob uma postura sistêmica.

\section{Palavras-chave}

Dança. Cultura Popular. Abordagem Sistêmica. Gesto.
Abstract

The present article aims to analyze the possibility of articulating the principles that constitute the expressive gesture study practices with investigations in the field of popular cultures' dances. For such, we assume the systemic perspective of knowledge production. The question that guided the investigation was: is it possible that the tools of body comprehension in dance - to which we have access through the studies that impregnate contemporary pedagogies in dance - act in a systemic approach as they relate to the making of popular dance? We sought the reflexive exercise from a documental research with references that deal with movement learning in the dance field and with the universe of Brazilian popular dances. We highlight the publications of Christine Roquet (2011), Antônio Nóbrega $(2013,1995)$ and Graziela Rodrigues (2005). This research was conducted from a referential which adresses the hologramatic and complex characteristic of human doings. With this study, it was possible to reflect on the work of artists that articulate with gestures of popular dances, as well as to base an argumentation in order to highlight what it means to work in dance under a systemic stance.

Keywords

Dance. Popular Culture. Systemic Approach. Gesture. 
Tempo do homem 1

A partícula cósmica que navega em meu sangue

é um mundo infinito de forças siderais. Veio a mim após um longo caminho de milênios.

Quando talvez eu tenha sido areia para os pés do ar.

Logo fui a madeira, raiz desesperada enterrada no silêncio de um deserto sem água.

Depois fui caracol, quem sabe onde.

$\mathrm{E}$ os mares me deram sua primeira palavra.

Depois a forma humana desfraldou sobre o mundo

a universal bandeira do músculo e da lágrima.

E cresceu a blasfêmia sobre a velha terra.

E o açafrão, e a tília, o verso e a oração.

Então, vim à América para nascer em homem.

E em mim juntei o pampa, a selva e a montanha.

Se um avô campeiro galopou até meu berço,

outro me disse histórias na flauta de taquara.

Eu não estudo as coisas, nem preten-

1 Tradução livre por Demétrio de Freitas Xavier (radialista, músico e pesquisador), da poesia "Tiempo Del Hombre" de Atahualpa Yupanqui. Segue o texto original: La partícula cósmica que navega en mi sangre/ es un mundo infinito de fuerzas siderales./Vino a mi tras un largo camino de milênios/ cuando, tal vez, fui arena para los pies del aire./ Luego fui La madera. Raíz desesperada./ Hundida em el silencio de un desierto sin agua./ Después fui caracol quién sabe dónde./Y los mares me dieron su primera palabra./ Después la forma humana desplegó sobre el mundo/ la universal bandera del músculo y la lágrima./Y creció La blasfemia sobre la vieja tierra./Y el azafrán, y el tilo, la copla y la plegaria./ Entonces vino a América para nacer en Hombre./ Y en mi junte la pampa, la selva y la montaña./ Si um abuelo llanero galopó hasta mi cuna,/ otro me dijo historias en su flauta de caña./ Yo no estúdio las cosas ni pretendo entenderlas./ Las reconozco, es cierto, pues antes vivi en ellas./ Converso con lãs hojas en medio de los montes/ y me dan sus mensajes las raíces secretas./ $Y$ así voy por el mundo, sin edad ni destino./ Al amparo de un Cosmos que camina conmigo./ Amo la luz, y el río, y el silencio, y la estrella./ Y florezco en guitarras porque fui la madera. do entende-las.

As reconheço, é certo, pois antes vivi nelas.

Converso com as folhas no meio dos matos

e me dão sua mensagem as raízes secretas.

E assim vou pelo mundo, sem idade nem destino.

Ao amparo de um cosmos que caminha comigo.

Amo a luz, e o rio, o silêncio, a estrela. $\mathrm{E}$ floresço em violões porque fui a madeira.

(AtahualpaYupanqui, 1976, n/p.)

É recorrente, na obra de Atahualpa Yupanqui $^{2}$, o tema do tempo: o tempo humano, o tempo dos fazeres humanos, o tempo dos fazeres humanos para além do tempo e do humano. Nessa poesia, o autor nos conta de um humano que faz o mundo à sua volta e se manifesta nesse mundo porque se reconhece nos lugares e nas coisas que o compõe. O texto nos leva a pensar nas coisas do "tempo do homem" como uma trama de significados que o ser humano constrói e que constitui o mundo à sua volta e que, ao mesmo tempo, constrói o ser humano.

Nesse sentido, o movimento do poema vai desenhando o que está relacionado ao tempo do homem (que entendemos aqui como o complexo da cultura), porém, algo mais nos versos atrai a nossa atenção: o ser humano identifica o que o constitui e o que o cerca, mas a poesia indica uma não separação entre o ser e as coisas. Ainda, o autor elucida, a todo momento, como o humano está sempre ao amparo de um cosmos que caminha junto a ele.

2 Atahualpa Yupanqui (1908 - 1992): artista argentino que compôs sua obra tecida no complexo e amplo campo cultural dos saberes populares. Obcecado pelo caminho, tornou-se um "viajante imparável". Em virtude da profundidade e amplitude de sua obra tornou-se capital simbólico argentino (MEDINA, 2008). 
Claramente são inesgotáveis os aspectos da relação entre homem e mundo que nos faz refletir a poesia e não temos a pretensão de encerrá-los nesta discussão. Mas, sim, ela abre esta pesquisa porque nos provoca a assumir cultura e ser humano como elementos de uma mesma totalidade, apontando a uma perspectiva hologramática ${ }^{3}$, na qual cada elemento é o todo e, ao mesmo tempo, constitui parte do todo. Fundamento importante para seguir a reflexão sobre as formas de aprendizagem entre o ser humano e seus processos culturais, uma vez que nessa relação reside a questão central deste artigo.

Buscamos, por meio de um exercício reflexivo, a partir de uma pesquisa documental, estudar acerca das possibilidades de aprender dança enquanto um fazer cultural humano. Isso, sem perder de vista a característica hologramática e complexa que apontamos acima. Eis que a poesia nos inspira uma vez mais a ampliar nosso horizonte de significados quando apresenta a possibilidade de não estudar nem pretender entender a cultura (os fazeres do ser humano), mas, sim, assumir o aprender como a ação de reconhecer-se naquilo que já viveu. Ou seja, reconhecer-se no todo que é o universo da cultura.

A fim de desenvolver este estudo, buscamos referências que trabalham a aprendizagem de movimento no campo da dança e o universo das danças populares brasileiras de forma coerente com as características sublinhadas acima. Das leituras surge o estreitamento da questão na seguinte pergunta: é possível que

3 O holograma refere-se a uma organização subjacente ao Cosmos. "Nos ensinamentos metafísicos do Antigo Egito e na máxima hermética 'assim em cima como embaixo', eles descreviam o espelhamento holográfico por 'autossimilaridade' do mundo manifesto em todas as escalas de existência." (LASZLO; CURRIVAN, 2010, p. 36). as ferramentas de compreensão do corpo na dança - às quais temos acesso pelos estudos que impregnam as pedagogias contemporâneas em dança - operem numa abordagem sistêmica ao se relacionarem com o fazer da dança popular?

Cabe aqui fazermos um destaque sobre o que entendemos sobre dança popular. O pesquisador Oswald Barroso (2013, p. 307-308), nos inspira a compreender a dança popular como uma forma cênica característica de dadas comunidades sociais:

A primeira das características, destas formas cênicas, pode ser resumida, dizendo-se que elas são parte da vida, isto é, têm suas atividades estreitamente integradas ao cotidiano das comunidades onde aparecem, seja aos ciclos agrícolas ou naturais, seja ao calendário festivo religioso. Trata-se, no geral, de apresentações originalmente protagonizadas por integrantes da comunidade, onde a separação entre atores e plateia não se faz de modo rígido.

Ou seja, a dança que nos propomos a entender como popular é aquela que acontece por ser um fazer constituinte da sua comunidade, por serem dança, sujeito e comunidade partes da mesma totalidade e totalidades em si que contém cada parte (retomando a perspectiva hologramática destacada acima pelo poema que abre a pesquisa). Um exemplo disso é que nessa forma cênica o público é também conhecedor da dinâmica própria da dança que se desenvolve, assim, o que leva o espectador a contemplar o fenômeno não é a expectativa do desfecho da cena, mas sim assistir e participar daquele evento enquanto uma celebração da comunidade. Outra característica marcante desse fazer popular funda-se na ideia de que as narrativas e os gestos expressos pela 
dança estão apoiados no imaginário coletivo emergente da história e do cotidiano comunitário (BARROSO, 2013).

Os aspectos citados acima direcionam nosso entendimento sobre dança popular como uma forma de expressão humana que se produz em virtude da habilidade dos coletivos humanos de criar e recriar "tudo aquilo que, existindo como forma peculiar de sentir e pensar o mundo, existe também como costumes e regras de relações sociais" (BRANDÃO, 1982 p. 30). São as expressões materiais e humanas do saber, do agir e do fazer popular que se mantém vivas pelo cotidiano e pelas celebrações comunitárias (BRANDÃO, 1982).

Assim, no que perpassa o discurso acerca da classificação em dança, muitas vezes são sinônimos de dança popular, as danças folclóricas e tradicionais; para fins desse estudo, assumimos distinções para estes sinônimos em relação à dança popular que descrevemos acima. Julgamos pertinente destacar que não é nosso objetivo apresentar aqui uma discussão profunda acerca destes temas, muito menos temos a pretensão de apresentar uma definição final sobre estes. Mas sim, propomos estabelecer uma conversa entre as características do universo da dança popular e perspectivas de estudo que nos permitem compreendê-lo.

Primeiramente, buscamos um afastamento da ideia de folclore, influenciada por um pensamento positivista, como um repertório de elementos que visa representar um grupo determinado, com identidade única e um passado inacessível, bem como do uso destes elementos com a função de criação de projetos de nação. Muitas vezes esse uso é percebido na história, a citar, o movimento armorial cunhado por volta de 1970 no Brasil, por Ariano Suassuna, como uma política cultural a formar uma unidade brasileira vinda do povo, por meio do trabalho com as manifestações como Maracatus, Bois, Escolas de Samba, entre outras (MARQUES, 2008). Ou ainda, na Argentina, o projeto que estabelece o ensino das danças folclóricas nas escolas. Tal projeto permite que todo argentino que tenha freqüentado o sistema escolar nesse país conheça e considere certas danças como parte de sua história, porque elas seriam parte da história que identifica o seu país como uma unidade nacional. Isso, ainda que a Argentina seja um país com enormes dimensões e iguais diversidades de fazeres e saberes.

Também não nos contempla aqui a ideia de danças tradicionais quando estas evocam o sentido conservador de algo, a necessidade de mantermos vivos, ainda que de maneira institucionalizada, fazeres ancestrais, muitas vezes deslocados dos seus contextos e dinâmicas próprias. Um dos motivos que nos leva a assumir essa postura é porque não estamos vinculados apenas aos produtos (a dança, por exemplo) mas sim a toda a complexidade do conjunto de saberes e fazeres, que estão: nos, entre, através e além dos fenômenos culturais.

Então, assumimos aqui, a expressão "dança popular" para nos referirmos a fazeres em dança que estão, como mencionado, ligados às dinâmicas da vida cotidiana de diferentes grupos de pessoas e que não têm, na sua gênese, vinculação institucional formal, principalmente no que diz respeito à sua criação, manutenção e ensino. Ainda, ao longo do texto, quando utilizamos a expressão "cultura popular" buscamos destacar o espectro mais amplo e a complexidade do fenômeno dança popular.

Assim, propomos refletir acerca dos fazeres de culturas populares a partir de uma abordagem sistêmica a qual também podemos ob- 
servar em práticas que se propõem a analisar o movimento dançado. Todavia, entendemos que o ato de analisar, em certo sentido, é contraditório a uma perspectiva sistêmica; então, justamente, essa é uma das reflexões que colocamos adiante: o desafio de aprender um gesto dançado, como fragmento de algo (que emerge de um universo complexo de dança popular), sem, com isso, desconsiderar que o menor fragmento porta, em si, o todo.

A pesquisadora Christine Roquet nos inspira à medida que apresenta em seu artigo uma ideia de transitar da prática de análise a uma percepção sistêmica do gesto expressivo. Com isso, o estudo da dança abre-se para "uma visão holística do 'corpo', e de um pensamento do processo que evita hierarquizar as noções de central/periférico ou profundo/ superficial, por exemplo" (2011, p. 13). Nesses termos, este estudo propõe um olhar sistêmico para abordagens sistêmicas, especificamente no ambiente das danças populares.

Antônio Nóbrega ${ }^{4}$ encontra, nas danças populares, uma gestualidade brasileira, tanto a partir do que ele chama de vocabulário (partes de movimentos que podem ser percebidas em cada dança), como por meio do temperamento ou do "jeitão", segundo o artista, que cada dança carrega. Temos, por meio dos estudos do Antônio Nóbrega, um meio de acessar a dança popular que é constituída por essa perspectiva hologramática. Por um lado, existe a possibilidade de encontrar o gesto a partir da percepção do detalhe do movimento dan-

4 Antônio Nóbrega é um multiartista brasileiro que articula dança, música, poesia e mímica. Dedica-se a levar para a cena uma dança concebida a partir de vivências em danças populares brasileiras a que teve acesso pelo convívio com inúmeros artistas populares. Sobre as manifestações culturais, o artista aponta: "e se você vai descascando a história dessas formas de expressão artística, vai encontrar, lá na sua raiz mais profunda, a seiva coletiva que a tudo fecunda" (NÓBREGA In: COELHO; FALCÃO, 1995, p.68). çado, por essa percepção é possível encontrar fragmentos de movimentos dotados de significados e que, juntos no corpo, constroem uma dança. Na outra ponta, está o temperamento ou "jeitão", onde se move o vocabulário. Não pode ser particionado, diz respeito ao todo que está em cada gesto. Segundo o artista, a união de ambas as dimensões compõe a expressividade da dança popular brasileira. (NÓBREGA, 2013.)

Assim, os pesquisadores acima nos inspiram a considerar a percepção de movimento que transcende hierarquizações enquanto uma prática que contribui para aprender dança. Igualmente nos convidam a transcender a análise e ir em direção a uma ótica sistêmica, ou seja, que considere a lógica do todo como única e muito mais que a soma de suas partes. Acerca disso Capra e Luisi (2014, p. 96) indicam que:

O pensamento sistêmico "é contextual", que significa o oposto do pensamento analítico. Análise significa separar as partes e considerar isoladamente uma delas para entendê-la; o pensamento sistêmico significa colocá-la no contexto de uma totalidade maior.

No campo da dança, destacamos, como uma possibilidade, a perspectiva de estudo em que os gestos, porque dotados de caráter expressivo, não podem ser dissociados do seu contexto. Esse entendimento funciona como meio para "esclarecer as interações entre gestos, posturas e o sentir da corporeidade, interações imaginárias em presença e no meio ambiente" (ROQUET, 2011, p. 13).

Percebemos que criações artísticas inspiradas na cultura popular - como as presentes nas obras de Antônio Nóbrega e Graziela Rodrigues - levam em conta o mais particular e 
o mais universal em relação ao dançante. Em dança, isso pode se referir, por exemplo, à propriocepção do intérprete e ao caráter simbólico do gesto expressivo.

Uma perspectiva sistêmica acerca dos fazeres da cultura popular

Toda cultura veicula uma concepção do humano, do divino e do cósmico, já que a própria realidade é constituída por essas três dimensões e pelas relações existentes entre elas. (COLL, 2002, p.37).

Entendemos, aqui, cultura popular como a cultura do povo para além da academia e seus pressupostos ${ }^{5}$, um complexo de fazeres e saberes arraigados a um modo de existir e transitar pela vida. Sensivelmente ligada a um senso prático de existência, de movimento e fruição, é algo demasiado grande e pertencente à vida. Por essa razão, fica difícil divisarmos suas fronteiras e, mais difícil ainda, definirmos ou trazermos à luz da consciência, porém está lá, constitui-nos e, ao mesmo tempo, é constituída por nós, estejamos conscientes ou não.

\footnotetext{
5 Conforme já foi apontado, a noção de cultura popular muitas vezes está vinculada à criação de categorias a fim de identificar grupos de pessoas segundo seus modos de vida. Tais classificações, não raro, são estruturadas por meio de metodologias provenientes de estudos acadêmicos (tal como as metodologias utilizadas pelos estudos folclóricos divulgados a partir do final do século XIX, no Brasil) e constituem-se a partir de um olhar externo a esse modo de vida (ABREU, 2003). Ainda, é frequente que a identificação de grupos sociais ditos populares se estruture a partir da sua produção material como vestimentas, alimentos, objetos de uso diário, etc. tendo em vista que são aspectos de mais fácil percepção para o olhar de quem não pertence ao grupo, mas que busca compreendê-lo. Porém, na perspectiva desse estudo, a cultura popular, ou seja, a cultura de um grupo de pessoas constitui-se inclusive por aquilo que não pode ser percebido por quem não integra o grupo, desde esse ponto descende a necessidade de destacar uma perspectiva sistêmica que permita compreender a cultura do outro para além da sua produção material e daquilo que mais se destaca como modo de vida; mais ainda, nos possibilite compreender que todas as lógicas e modos de fazer dos grupos sociais são constituintes da sua cultura.
}

Talvez fosse dispensável categorizar como popular, mas, para a pesquisa, pensamos que é importante que tratemos acerca do recorte "popular", porque estamos tratando de um caráter expressivo da cultura que se dá principalmente em festas, celebrações, rituais, ligados à tradição e circunscritos por diferentes nichos comunitários.

Então, nas práticas da cultura popular, percebemos que, em muitos casos, os fazeres são praticamente indescritíveis pelos próprios praticantes, dada a dificuldade do indivíduo separar-se do que é. Isso nos indica uma postura sistêmica frente a tais conhecimentos. Assim, é comum ouvir expressões como: "eu sempre soube", "ninguém me ensinou", "sempre aconteceu assim", "está na minha cabeça", etc.

Meu nome é Edite José da Silva [...] Tenho 60 anos de idade, gosto de dançar ciranda, gosto de cantar, gosto de me apresentar, gosto de falar, gosto de escutar [...] na minha ciranda e no coco de roda que eu canto porque isso foi coisa que ninguém nunca me ensinou, ninguém nunca me ensinou, isso é coisa que foi criada do meu coração e então dos antepassados, dos meus tataravós, dos meus avós, foi que nem diz o ditado, e vieram passando de geração pra geração e até hoje eu estou cantando ciranda" [...] (BARCA, 2005).

Tanto pela fala de Edite José da Silva, cirandeira de Alagoa Grande - Paraíba, quanto pela poesia que abre esta pesquisa, entendemos que se destaca um acesso ao conhecimento pelo todo, por estar imbricado na cultura. A ciranda é parte de Edite, assim como foi criada em seu coração. Esta afirmação permite perceber uma aproximação tal entre o sujeito e o fazer cultural como duas partes inseparáveis, íntimas. O coração que sustenta o sujeito é o mesmo que cria a manifestação cultural. 
Da mesma forma, quando o poeta aponta "Eu não estudo as coisas, nem pretendo entendê-las. As reconheço, é certo, pois antes vivi nelas." (YUPANQUI, 1976), ele remete a um saber que emerge porque o sujeito reconhece-se no todo, vive em tal conhecimento. Essa postura junto ao mundo e às coisas que se pretende conhecer enuncia um processo recursivo para as aprendizagens culturais que envolvem os sujeitos.

Um processo recursivo é um processo onde os produtos e os efeitos são ao mesmo tempo causas e produtores do que os produz... A ideia recursiva é, pois, uma ideia em ruptura com a ideia linear de causa/efeito, de produto/produtor, de estrutura/superestrutura, já que tudo o que é produzido volta-se sobre o que produz num ciclo ele mesmo autoconstitutivo, auto-organizador e autoprodutor (MORIN, 2006, p.74).

As produções de conhecimento correntes nas práticas populares guardam mais semeIhança com a ideia de processo recursivo do que com uma noção sistematizada e linear de aprendizagem, na qual existe um programa pré-determinado de conteúdos e atitudes, que visam a um resultado também pré-determinado do que será aprendido. Ao contrário, então, porque assumimos que um caráter recursivo e sistêmico é coerente com os fazeres da cultura popular, também percebermos que esta é uma perspectiva possível para aprender acerca da dança que emerge de tal cultura.

É importante destacar que consideramos, nesta reflexão, uma distinção entre o universo das práticas das culturas populares e a arte de articular, no corpo, inspirações da cultura popular com intuito de levá-las para a cena destacadas do seu espaço de origem como uma ação profissional em arte. Assim, ao nos referirmos aos fazeres da cultura popular, temos em mente as práticas que são realizadas pelos sujeitos próprios de cada cultura, ou seja, os brincantes ${ }^{6}$ dos reisados, os foliões do carnaval, etc.; são indivíduos que têm os saberes das festas incorporados (BARROSO, 2013).

Estes sujeitos brincantes diferem dos profissionais da arte no sentido de que as festas, as celebrações, os gestos, as danças estão incorporados e são inseparáveis da vida dos brincantes. Já o profissional que articula a linguagem da cultura popular como inspiração para a cena desloca-se do seu cotidiano para imergir na cultura do brincante em busca de elementos para constituir suas criações. Ele caminha em direção ao complexo vivido pelos brincantes no sentido de encontrar possibilidades de se reconhecer também em parte de tal universo. Ele encontra-se em meio ao desafio, tal qual nos descreve Antônio Nóbrega (2013), de perceber e os movimentos, trejeitos, temperamento entre outros elementos que compõem as diversas dimensões da expressividade dos brincantes.

Assim, a transformação da cultura dos brincantes em movimento dançado, realizada por quem tem sua arte inspirada por ela, caracteriza-se pela "busca de uma realidade gestual como proposta estética dentro da poética de um corpo flexibilizado, escrito, musicado e entendido como humano" (FUSER, 2005 p. 13). Assim, os profissionais da arte interagem com manifestações populares e incorporam gestos, expressividades, temperamento e movimento a fim de compor sua cena.

6 Para um maior esclarecimento, o termo brincante refere-se ao "brincador, participante de folguedo folclórico, ou auto popular, ou de qualquer folia, como o carnaval" (HOUAISS, 2009, p. 513). 


\section{Sobre aprender dança popular:} entre a parte e o todo

Discutimos, aqui, sobre a aprendizagem desse profissional artista que escolhe se aproximar da dança popular por meio do detalhe do movimento bem como da compreensão do todo. $O$ todo não se refere apenas à manifestação cultural que está sendo aprendida, ao contexto social e/ou seu entorno, mas à totalidade: o "tudo", indivisível, imenso e complexo.

Logo, ao referirmos que aprendemos de forma sistêmica, não indicamos apenas que o processo se dê por olhar as partes e considerar o todo. Isso igualmente é analítico, não passa de uma análise contextualizada ${ }^{7}$. O que propomos é que não seja necessário lembrar-se de considerar o todo, pois, desde a partida, a noção do todo é tão profunda e arraigada em nós que sua lógica é presente, inclusive quando colocamos o foco em alguma parte constituinte.

Ainda, além de perceber o entorno, a lógica do todo abarca aquilo que não pode ser percebido, mas não por isso deixa de existir. Assim, uma característica importante dessa perspectiva é que não há a intenção nem a necessidade de mensurar tal totalidade ou de nomeá-la. O todo é também inominável. Sob a perspectiva sistêmica, não é desejável nem possível tornar consciente cada elemento do todo, uma vez que o todo é constituído também do que não é perceptível.

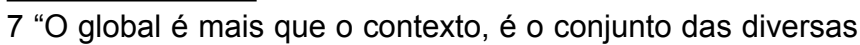
partes ligadas a ele de modo inter-retroativo ou organizacional. Dessa maneira, uma sociedade é mais que um contexto: é o todo organizador de que fazemos parte. O planeta Terra é mais do que um contexto: é o todo ao mesmo tempo organizador e desorganizador de que fazemos parte. O todo tem qualidades ou propriedades que não são encontradas nas partes, se estas estiverem isoladas umas das outras, e certas qualidades ou propriedades das partes podem ser inibidas pelas restrições provenientes do todo." (MORIN, 2005, p. 37)
$\mathrm{Na}$ abordagem sistêmica, as propriedades das partes só podem ser compreendidas a partir da organização do todo. Em conformidade com isso, o pensamento sistêmico não se concentra em blocos de construção básicos, mas, em vez disso, em princípios de organização básicos (CAPRA; LUISI, 2014, p. 96).

A produção de conhecimento concentrada em princípios, e não em blocos, indica uma postura aberta e atenta à complexidade inerente aos fenômenos, o que, em nossa perspectiva, é coerente com a produção de conhecimento em arte. Além disso, como a matéria do trabalho artístico é simbólica, mantém-se ativo o caráter dinâmico e plural da fonte de inspiração.

A maneira com que o artista se relaciona com o material simbólico de inspiração está intimamente ligada à elaboração do movimento expressivo. Isso é fruto do trabalho e da concepção de processo formativo que cada artista desenvolve para além do momento da cena, mas que compõe a expressão do movimento. Segundo Roquet (2011, p. 8), a formação do bailarino, num sentido amplo, envolve diferentes atividades psíquicas, somáticas, perceptivas, dentre outras atividades corporais em constante interação e com a finalidade de "elaborar um pensamento do gesto e os discursos para acompanhá-lo".

Quando o material simbólico emerge da cultura popular, é necessário estar atento para não limitar o caráter aberto, dinâmico e plural das manifestações. Roberta Ramos, por exemplo, sugere que $o$ trabalho fixado em organizar as danças em passos específicos reforça o argumento de que a cultura popular "se preserva na repetição e na manutenção do que ela era antes do presente" (RAMOS, 2011, p. 94). A autora pondera que a organização da dança 
em passos se caracteriza como uma estrutura fixa em relação ao movimento e, assim, produz "um discurso altamente controlado" (RAMOS, 2011, p. 94). Nestes termos, o trabalho centrado a partir de células fixadas de movimento (os passos) pode provocar ao menos duas interpretações equivocadas: a) de que uma dança pode ser transportada "tal e qual" de um contexto a outro - de um corpo a outro, da rua para o palco italiano, etc; b) de que passos de dança são células fechadas de movimento, impermeáveis aos corpos, histórias e ambientes (dentre outros elementos) nos quais são produzidos.

As duas questões apontadas estão fortemente interligadas. Justamente porque qualquer sequência de movimento - parte de uma dança - é atravessada de infinitos constituintes no momento presente em que o movimento acontece. Ainda, cada movimento, por mais parecido que possa ser com outros, nunca é o mesmo. Então uma dança que ocorre numa manifestação cultural e por corpos integrantes de certa comunidade nunca poderá ser transferida "tal e qual" para corpos de outras comunidades e para outros contextos de manifestação. Entendemos, assim, que a organização de uma dança em passos pode ser efetiva de certa forma, mas é necessário reconhecer a limitação dessa perspectiva. Por este motivo, a ideia de uma aproximação sistêmica do fenômeno nos indica um caminho mais coerente.

No sentido que nos apontou Antônio Nóbrega acerca de um vocabulário emergente da dança brasileira, conforme já ponderamos acima, retomamos o esclarecimento de que um vocabulário de movimentos em dança está sempre acompanhado de um temperamento ou "jeitão". Dessa forma, temos o movimento como parte característica de uma manifes- tação popular que precisa carregar consigo o todo da manifestação para que tenha sentido.

Não importa o número de passos que você saiba (ou não), fazer o passo é uma forma de estar no meio do coro coletivo, no meio da tuba imensa, no meio da multidão até a quarta-feira de cinzas. Através do Carnaval, o passo do frevo é uma forma de comunhão dionisíaca com o mundo e os homens. (NÓBREGA, 1995, p. 67, grifo do autor)

Apresentamos a perspectiva do "passo", na dança, porque acreditamos ser uma ideia corrente nos estudos em dança popular, e parece-nos como um exemplo de acesso ao gesto dançado que muitas vezes tende a uma forma analítica de entender a dança. Porém, na citação acima, o artista nos apresenta uma outra possibilidade acerca do passo como constituinte da dança, assim podemos perceber que o limitante não é o passo ou o movimento em si, mas a abordagem com a qual nos relacionamos com este. Dessa maneira, o passo transita do status de produto para o de processo.

Para tanto, busca-se uma abordagem que considera, para além das questões ligadas às qualidades do movimento, a noção de algo maior e mais complexo, indivisível. Quanto a isso, Graziela Rodrigues situa a "dança como atividade em que vários corpos se integram para gerar conhecimento no âmbito do sensível, do perceptível e das relações humanas a partir de um contato direto com a realidade circundante" (RODRIGUES, 2005, p. 23).

Ainda, destacamos que nessa abordagem também reside a ideia de que toda a expressão de uma dança popular está pronta à medida que ela é celebrada. O gestual, em meio a uma festa popular, não precisa ser aprendido para apenas depois ser realizado, mas, sim, a aprendizagem se dá junto com a sua reali- 
zação. Todo movimento dessa dança acontece com o intento de fazer com que tal cultura popular aconteça e, desse intento, emergem os significados inerentes a cada movimento. Então, a perspectiva sistêmica contribui para a compreensão do fazer popular em dança como um fazer ligado aos fluxos naturais de cada comunidade que vive sua cultura.

Assim sendo, sugerirmos que uma perspectiva sistêmica para a produção de conhecimento em dança é adequada, inclusive, quando esta está articulada com saberes e fazeres das culturas populares.

Propomos, aqui, refletir a respeito da interação entre leitura de gesto e algumas características da expressão e movimento das danças populares. Este artigo não teve a pretensão de elaborar ou divulgar um sistema pedagógico para trabalho com danças populares a partir de metodologias de análises de movimento. Antes, desejamos dar um passo para trás, e apontar algumas questões acerca do que consideramos uma interação de saberes: aquilo que faz produzir os movimentos nos ambientes em que a dança popular acontece e a possibilidade, ou impossibilidade, de nos aproximarmos de tais movimentos sob a ótica da leitura do gesto expressivo.

Referências

ABREU, Martha. Cultura popular, um conceito e várias histórias. In: ABREU, Martha; SOIHET, Rachel. Ensino de História, Conceitos, Temáticas e Metodologias. Rio de Janeiro: Casa da Palavra, 2003.
BARCA, A. Direção: Angélica Del Nery. Produção: Angélica Del Nery, Lincoln Antonio, Patrícia Ferraz, Renata Amaral. São Paulo: Maracá e Cooperativa de música, 2005. 1 DVD (86 $\min$.)

BARROSO, Oswald. Teatro como encantamento: bois e reisados de caretas. Fortaleza: Armazém da cultura, 2013.

BRANDÃO, Carlos Rodrigues. O que é folclore. São Paulo: Editora Brasiliense S.A., 1982.

CAPRA, Fritjof; LUISI, Pier Luigi. A visão sistêmica da vida: uma concepção unificada e suas implicações filosóficas, políticas, sociais e econômicas. São Paulo: Cultrix, 2014.

COLL, Augustí Nicolau. Propostas para uma diversidade cultural intercultural na era da globalização. São Paulo, Instituto Pólis, 2002.

Instituto Antônio Houaiss. Dicionário Houaiss da língua portuguesa. Rio de Janeiro: Objetiva, 2009.

LASZLO, Ervin; CURRIVAN, Jude. Cosmos: unindo ciência e espiritualidade para um novo entendimento do universo e de nós mesmos. São Paulo: Cultrix, 2010.

MARQUES, Roberta Ramos. Deslocamentos Armoriais: da afirmação épica do popular na "Nação Castanha" de Ariano Suassuna ao corpo-história do Grupo Grial (primeira parte). Tese (Doutorado em Teoria da Literatura) Centro de Artes e Comunicação, Universidade Federal de Pernambuco, Recife, 2008. 
MEDINA, Mariano. Guia para Reencontrarse com Yupanqui. Córdoba: UPA! Músicos em Movimiento; Secretaria de Extensión de La Universidad Nacional de Córdoba; Fundación Atahualpa Yupanqui, 2008.

MORIN, Edgar. Introdução ao pensamento complexo. Porto Alegre: Sulina, 2006.

- Os sete saberes necessários à educação do futuro. São Paulo: Cortez; Brasília, DF: UNESCO, 2005.

NOBRÉGA, Antônio. Entrevista com Antônio Nóbrega. In: Lima, Dani. Gesto: práticas e discursos. Rio de Janeiro: Cobogó, p. 147-154, 2013.

Antônio Nóbrega: um artista multidisciplinar. In: COELHO, Marco Antônio; FALCÃO, Aluísio. Estudos Avançados, São Paulo, v. 9, n. 23, p. 59-70, jan./abr. 1995.

RAMOS, Roberta. Lembrar-esquecer: episódio criador da dança popular. In: NORA, Sigrid (Org.). Humus, 4. Caxias do Sul: Lorigraf, 2011.

RODRIGUES, Graziela E. F. Bailarino-pesquisador-intérprete: processo de formação. Rio de Janeiro: Funarte, 2005.

ROQUET, Christine. Da análise do movimento à abordagem sistêmica do gesto expressivo. O Percevejo online. Rio de Janeiro, v. 3, n. 1, p 1-15, jan./jul. 2011.

YUPANQUI, Atahualpa. El canto del viento. Buenos Aires: Ediciones Siglo Veinte, 1976.
Recebido: 14/04/2017 Aprovado: 30/06/2017 